\title{
Caracterização genética das leveduras de fermentação como elemento de Indicação Geográfica da cachaça e aguardente artesanais de Luiz Alves, SC
}

\author{
Valdir Marcos Stefenon', Bruna Ronchi Hermann², Julia Zappelini e Milena Martins Machado²
}

\begin{abstract}
Resumo - O município de Luiz Alves, SC, mantém tradições familiares na produção de cachaça e aguardente por alambiques artesanais, demandando processos de Identificação Geográfica para valorização do produto local e proteção do conhecimento tradicional associado. A fim de subsidiar a Identificação Geográfica dos produtos, o objetivo deste trabalho foi caracterizar, por bases moleculares, as leveduras nativas utilizadas por seis alambiques da região. Foram realizadas análises de três regiões genômicas: internal transcribed spacer (ITS), large subunit rRNA (LSU) e interdelta para comparação com a levedura comercial UFLA CA-11. Apesar da similaridade das sequências LSU/ITS de todas as leveduras nativas com Saccharomyces cerevisiae, inferências filogenéticas e análises de componentes principais da região interdelta demonstram diferenciação genética importante em relação à levedura comercial, além da singularidade entre as amostras de diferentes estabelecimentos. Os resultados apresentados são pioneiros na caracterização molecular de leveduras utilizadas no processo de produção de cachaças em SC visando à Identificação Geográfica dos produtos de Luiz Alves, e traz o potencial de uso destes marcadores moleculares no processo.
\end{abstract}

Termos de indexação: Indicação Geográfica; Marcadores moleculares; Diferenciação genética.

\section{Genetic characterization of fermentation yeasts as an element of geographical indication of 'cachaça' and 'aguardente' from Luiz Alves, SC}

\begin{abstract}
The municipality of Luiz Alves, SC, maintains familiar traditions of 'cachaça' and 'aguardente' production by artisanal distilleries, demanding Geographic Identification processes for the valorization of local products and protection of associated traditional knowledge. Aiming to subsidize the Geographical Identification of the products, the objective of this work was to characterize, by molecular basis, the native yeasts used by six distilleries in the region. Analysis of three genomic regions internal transcribed spacer (ITS), large subunit rRNA (LSU) and interdelta were performed for comparison with the commercial yeast UFLA CA-11. Despite the similarity of the LSU/ITS sequences of all yeasts with Saccharomyces cerevisiae, phylogenetic inferences and principal component analyzes of the interdelta region recovered important genetic differentiation in relation to commercial yeast, along with the uniqueness between samples from different establishments. The results present herein are pioneering in molecular characterization of yeasts used in production processes of cachaça in SC, aiming at the Geographic Identification of products of Luiz Alves and highlights the potential use of those molecular markers in the process.
\end{abstract}

Index terms: Geographic identification; Molecular markers; Genetic differentiation

Devido à qualidade da cachaça e aguardente artesanais produzidas em seus alambiques, o município de Luiz Alves ( $26^{\circ} 43^{\prime} 9^{\prime \prime}$ Sul, $48^{\circ} 56^{\prime} 36^{\prime \prime}$ 'Oeste) é reconhecido como "Capital Catarinense da Cachaça - Terra da Cachaça" pela Lei № 17.535 , de 19 de junho de 2018 do governo do Estado. Esses alambiques, na sua maioria estabelecidos há várias décadas, têm mantido as tradições familiares e transmitido, de geração a geração, tanto as técnicas de produção quanto as leveduras nativas utilizadas no processo de fermentação que origina a cachaça e a aguardente artesanais do município. Cachaça é o nome dado à bebida produzida partir da fermentação alcoólica e destilação do mosto da cana-de-açúcar com graduação alcoólica entre $38 \%$ a $48 \%$. Já a aguardente é o nome de qualquer bebida alcoólica obtida a partir da fermentação e destilação de vegetais doces, podendo também ser de cana, possuindo graduação alcoólica entre $38 \%$ a 54\% (BRASIL, 2009).

A Indicação Geográfica dessas bebidas produzidas pelos alambiques é um procedimento necessário para proteger o conhecimento agregado e a tecnolo- gia de produção adotada.

As cepas de Saccharomyces cerevisiae envolvidas em processos de fermentação de bebidas alcoólicas desempenham um papel importante nas características do produto final e são elementos centrais na Indicação Geográfica de bebidas destiladas (BARBOSA et al., 2016). Nessa perspectiva, o presente trabalho objetivou caracterizar molecularmente as leveduras nativas utilizadas no processo de produção de cachaça e aguardente artesanais pelos alambiques de Luiz Alves, de modo a subsidiar sua certificação de Indicação Geográfica.

${ }^{2}$ Estudante de graduação em Agronomia, UFSC, CCA, e-mail: brunaronchih@hotmail.com, milenamarti nsmachado@gmail.com,

${ }^{3}$ Engenheira-agrônoma, MSc, Doutoranda no Programa de Pós Graduação em Recursos Genéti cos Vegetais, UFSC, CCA, e-mail: juzapp@gmail.com 
Amostras de leveduras, melado de cana e caldo de cana foram coletadas em seis alambiques membros da Associação de Produtores de Cachaça Artesanal de Luiz Alves (APCALA). O acesso ao Patrimônio Genético foi cadastrado junto ao SISGEN sob número A91E0E4. As coletas foram realizadas em frascos individuais, previamente esterilizados, durante a fermentação do caldo de cana nos seis alambiques (LA01, LA02, LA03, LA05, LA06 e LA08). Alíquotas de 30g de cada levedura coletada nos alambiques e da levedura comercial selecionada UFLA CA-11 (Angel Yeast Co., Hubei, China) foram cultivadas individualmente em meio líquido composto por $55 \mathrm{~mL}$ de melado, $50 \mathrm{~mL}$ de caldo de cana e $195 \mathrm{~mL}$ de água destilada, em frascos Erlenmeyer de $500 \mathrm{~mL}$ a $30^{\circ} \mathrm{C}$. Após o cultivo por 24 horas, alíquotas de $50 \mathrm{~mL}$ de cada amostra foram centrifugadas, o sobrenadante foi descartado e o sedimento foi empregado para isolamento do DNA total utilizando o DNeasy Plant Mini Kit (Qiagen). A qualidade e a quantidade do DNA isolado foram avaliadas em um sistema de espectrofotometria NanoDrop (Thermo Fisher Scientific).

As regiões genômicas, internal transcribed spacer (ITS) e large subunit rRNA (LSU), foram amplificadas utilizando os iniciadores ITS1/ITS4 e LSULRO9R/LSU-LR5 (HOANG et al., 2019), respectivamente, visando identificar a espécie (ou espécies) de levedura envolvida no processo de fermentação. Os fragmentos amplificados foram purificados via polietilenoglicol (PEG), ressuspendidos em $10 \mu \mathrm{L}$ de água ultrapura e utilizados como DNA-alvo para uma nova amplificação com os mesmos iniciadores. Os produtos da segunda amplificação foram novamente purificados via PEG e empregados para a reação de sequenciamento utilizando a tecnologia BigDye ${ }^{\mathrm{TM}}$ Terminator (Thermo Fisher Scientific) em um equipamento ABI 3730xL (Applied Biosystems). As sequências geradas foram identificadas através da técnica BLAST contra sequências depositadas no GenBank/NCBI. $O$ alinhamento das sequências foi realizado utilizando-se o algoritmo MUSCLE e uma árvore filogenética foi construída na plataforma digital EMBL-EBI (https:// www.ebi.ac.uk).

Tendo por base as relações filoge- néticas determinadas pela região LSU, as amostras LA01, LA05, LA06, LA08 e CA-11 foram caracterizadas através da análise da região genômica interdelta, visando identificar diferenças genéticas específicas entre as amostras. A amplificação via reação de PCR foi realizada utilizando os iniciadores delta2 e delta12 (LEGRAS \& KARST, 2003). Os fragmentos amplificados foram separados via eletroforese em gel de agarose $2 \%$, corados com GelRed ${ }^{\circledR}$ (Biotium) e visualizados sob luz UV. Os fragmentos amplificados foram codificados binariamente de acordo com sua presença ou ausência (1/0) em cada amostra. A matriz binária proveniente desta avaliação foi utilizada para calcular uma matriz de distância Euclidiana, empregada em uma análise de componentes principais (PCA) e para a construção de um dendrograma baseado no algoritmo UPGMA com 1000 repetições bootstrap, ambas usando o software Past 4.03 (HAMMER et al., 2001).

A análise BLAST das sequências das regiões genômicas das leveduras apontou Saccharomyces cerevisiae como a espécie com maior similaridade com todas as amostras, variando de $89,17 \%$ a $99,89 \%$ para a região LSU e de $84,35 \%$ a $97,44 \%$ para a região ITS.

A análise filogenética das amostras baseadas nas sequências da região ITS (Figura 1A) agrupou as duas cópias da levedura CA-11 separadas das leveduras nativas, demonstrando a diferença molecular existente entre essas amostras. Já a região LSU apresentou um padrão semelhante, mas agrupando CA-11 com a levedura nativa LA08 (Figura 1B). Este agrupamento das amostras LA08 e CA11 sugere uma possível "contaminação" da levedura nativa com a levedura co-

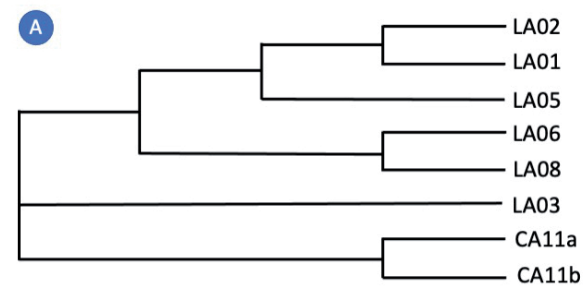

Figura 1. Inferências filogenéticas das regiões barcode ITS (A) e LSU (B) do genoma das leveduras nativas (LA01-LA08) e comercial (CA11a e CA11b)

Figure 1. Phylogenetic inferences of barcode regions ITS $(A)$ and $L S U$ (B) from native (LA01LAO8) and commercial (CA11a and CA11b) yeasts genomes

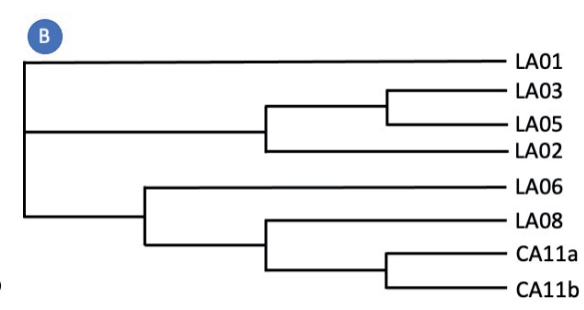

mercial, devido à utilização da CA-11 nos tanques de fermentação. Essa possibilidade é reforçada pela aparência física da amostra LA08 cultivada no laboratório, a qual apresentou características intermediárias entre a levedura CA-11 e as outras leveduras nativas (dados não apresentados) e pelos relatos dos produtores de cachaça.

A análise da região interdelta confirmou a diferença entre as leveduras nativas e a comercial (Figura $2 \mathrm{~A}$ ), além de demonstrar diversidade entre as leveduras nativas. A análise de agrupamento (Figura 2B) e a PCA (Figura 3C) claramente expressam essas diferenças. O eixo da componente 1 , principal responsável pela diferenciação da amostra CA-11 com relação às demais amostras (Figura 2C), representa $68 \%$ da variação total.

Vários estudos utilizando marcadores moleculares têm demonstrado a presença de linhagens variantes de $S$. cerevisiae em alambiques de cachaça artesanal da região Sudeste do Brasil (BARBOSA et al., 2016; ARAÚJO et al., 2018). Por sua vez, Badotti et al. (2010) demonstraram que leveduras coletadas em alambiques de diferentes estados do Brasil apresentam padrões genéticos diferentes e exclusivos. Diferentes cepas nativas de $S$. cerevisiae desenvolvem-se durante o período de produção, e cada uma contribui diferentemente para a qualidade da cachaça (FERREIRAD'SILVA et al., 2019). Este fundamento é um dos elementos capazes de basear a Indicação Geográfica de bebidas artesanais. Com base na análise de três regiões genômicas, demonstrou-se que as leveduras nativas utilizadas nos alambiques de Luiz Alves são singulares e distintas da levedura comercial CA-11. 


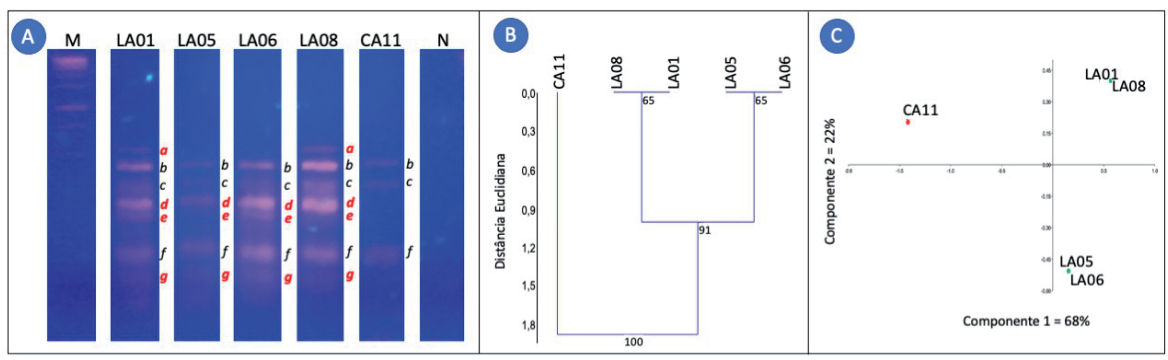

Figura 2. Análises da região interdelta. (A) Gel de eletroforese da região interdelta das leveduras nativas e comercial. Os fragmentos presentes nas leveduras nativas e ausentes na levedura comercial estão destacados em vermelho. N: controle negativo. M: marcador de peso molecular. (B) Análise de agrupamento UPGMA. Os valores juntos aos nós representam o suporte Bootstrap. (C) Análise de componentes principais Figure 2. Analyses of the interdelta region. (A) Electrophoresis gel of the interdelta region of the native and commercial yeasts. Fragments present in native yeasts and absent in commercial yeast are highlighted in red. $\mathrm{N}$ : negative control. M: molecular weight ladder. (B) UPGMA clustering analysis. Values at the nodes represent the Bootstrap support. (C) Principal component analysis
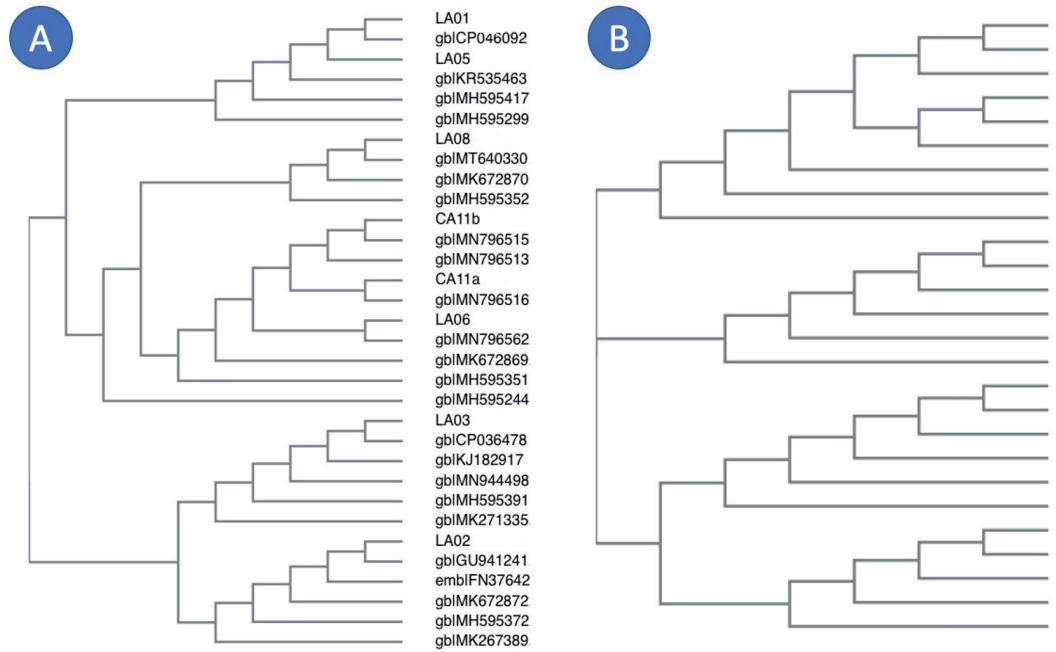

Figura 3. Árvore filogenética das amostras de levedura incluídas neste estudo e de sequências provenientes do GenBank para as regiões barcode ITS (A) e LSU (B), após a análise BLAST

Figure 3. Phylogenetic tree of the yeast samples included in this study and sequences form the GenBank for the barcode regions ITS (A) and LSU (B) after the BLAST analysis

Dessa forma, as cepas nativas de $S$. cerevisiae utilizadas na fermentação, aliadas à forma de produção desenvolvida ao longo dos anos pelos alambiques do município, tem potencial influência nas características organolépticas da bebida produzida e podem ser utilizadas como marcadores para a Indicação Geográfica da cachaça e aguardente artesanais de Luiz Alves. Além disso, observa-se a existência de diversidade genética entre as amostras de leveduras nativas de cada alambique, fato que também proporciona o diferencial entre as bebidas produzidas por cada estabelecimento.

\section{Agradecimentos}

Os autores agradecem ao Sebrae pelo aporte financeiro, à Prefeitura do Município de Luiz Alves e à APCALA pelo apoio logístico.

\section{Referências}

ARAÚJO, T.M., SOUZA, M.T.; DINIZ, R.H.S.; YAMAKAWA, C.K.; SOARES, L.B.; LENCZAK, J.L.; DE CASTRO OLIVEIRA, J.V.; GOLDMAN, G.H.; BARBOSA, E.A.; CAMPOS, A.C.S.; CASTRO, I.M.; BRANDÃO, R.L. Cachaça yeast strains: alternative starters to produce beer

and bioethanol. Antonie van Leeuwenhoek, v.111 n.10, p.1749-66, 2018. DOI: https:// doi.org/10.1007/s10482-018-1063-3

BARBOSA, E.A.; SOUZA, M.T.; DINIZ, R.H.S.; GODOY-SANTOS, F.; FARIA-OLIVEIRA, F.; CORREA, L.F.M.; ALVAREZ, F.; COUTRIM, M.X.; AFONSO, R.J.D.C.F.; CASTRO, I.D.M.; BRANDÃO, R.L. Quality improvement and geographical indication of cachaça (Brazilian spirit) by using locally selected yeast strains. Journal of Applied Microbiology, v.121, n.4, p.1038-1051, 2016. DOI: https://doi. org/10.1111/jam.13216

BADOTTI, F.; BELLOCH, C.; ROSA, C.A.; BARRIO, E.; QUEROL, A. Physiological and molecular characterisation of Saccharomyces cerevisiae cachaça strains isolated from different geographic regions in Brazil. World Journal of Microbiology and Biotechnology, v.26, n.4, p.579-587, 2010.

BRASIL. Presidência da República. Casa Civil. Decreto no 6.871, de 4 de junho de 2009. Brasília, DF, 2009.

FERREIRA-D'SILVA, A.; BADOTTI, F.; PINHEIRO, C.S.R.; GONÇALVES, C.M.; HUGHES, F.M.; GÓES-NETO, A.; UETANABARO, A.P.T. Diversity of Saccharomyces cerevisiae strains isolated of the spontaneous fermentation of cachaça from northeastern Brazil. Brazilian Journal of Development, v.5, n.11, p.274482746, 2019.

HAMMER, $\varnothing$.; HARPER, D.; RYAN, P.D. Past: paleontological statistics software package for education and data analysis. Palaeontologia Electronica, v.4, p.1-4, 2001.

HOANG, M.T.V.; IRINYI, L.; CHEN, S.C.A.; SORRELL, T.C.; THE ISHAM BARCODING OF MEDICAL FUNGI WORKING GROUP; MEYER, W. Dual DNA Barcoding for the Molecular Identification of the Agents of Invasive Fungal Infections. Frontiers in Microbiology, v.10, n.1647, 2019. DOI: https://doi.org/10.3389/ fmicb.2019.01647 